\title{
EVALUASI KERUSAKAN PERKERASAN LENTUR DENGAN METODE PCI DAN SDI (STUDI KASUS: JALAN JATISARI, KARAWANG)
}

\author{
Ricky Hermawan ${ }^{1}$ dan Anissa Noor Tajudin ${ }^{2}$ \\ ${ }^{1}$ Program Studi Sarjana Teknik Sipil, Universitas Tarumanagara, Jl. Letjen S. Parman No.1 Jakarta \\ ricky.325160065@stu.untar.ac.id \\ ${ }^{2}$ Program Studi Sarjana Teknik Sipil, Universitas Tarumanagara, Jl. Letjen S. Parman No.1 Jakarta \\ anissat@ft.untar.ac.id
}

Masuk: 10-07-2021, revisi: 19-11-2021, diterima untuk diterbitkan: 19-11-2021

\begin{abstract}
Large vehicles that repeatedly pass a road cause damage to the pavement of the Jatisari National Road, Karawang. Various pavement damage that occurs such as holes, patches, crocodile skin cracks, groove cracks, sungkur, roadside cracks, and subsidence. Pavement Condition Index (PCI) is a method commonly used to indicate the condition of road pavement, so that it can be known good handling to maintain the pavement. The Surface Distress Index (SDI) method can also be used to indicate the condition of the road surface. With the PCI method, the results of the calculation in the Pamanukan direction are classified as perfect at 78\%, very good 14\%, good 4\% and moderate 4\%. while the Cikampek direction is classified as perfect at 74\%, very good $12 \%$, good $8 \%$, moderate $4 \%$, and bad 2\%. Using the SDI method, good results were obtained for both directions. Based on the results of the analysis, research using the PCI and SDI methods showed different results, because the PCI method observed all the damage that occurred on the pavement, while the SDI method only observed 4 elements of damage, so the results displayed were different.
\end{abstract}

Keywords: PCI; SDI; Road

\begin{abstract}
ABSTRAK
Kendaraan besar yang berulang kali melewati sebuah jalan menyebabkan kerusakan pada perkerasan Jalan Nasional Jatisari, Karawang. Berbagai Kerusakan perkerasan yang terjadi seperti, lubang, tambal, retak kulit buaya, retak alur, sungkur, retak tepi jalan, dan amblas. Pavement Condition Index (PCI) merupakan metode yang biasa digunakan untuk menunjukkan kondisi perkerasan jalan, sehingga bisa diketahui penanganan yang baik untuk memelihara perkerasan jalan tersebut. Selain itu, digunakan metode Surface Distress Index (SDI) untuk menunjukkan kondisi permukaan jalan. Dengan Metode PCI, hasil perhitungan pada arah Pamanukan digolongkan sempurna sebesar 78\%, sangat baik $14 \%$, baik $4 \%$ dan sedang $4 \%$. sedangkan pada arah Cikampek digolongkan sempurna sebesar $74 \%$, sangat baik $12 \%$, baik $8 \%$, sedang $4 \%$, dan buruk 2\%. Dengan metode SDI, diperoleh hasil Baik untuk kedua arah jalan. Berdasarkan hasil analisis, penelitian menggunakan metode PCI dan SDI menunjukkan hasil yang berbeda, dikarenakan dalam metode PCI mengamati semua kerusakan yang terjadi pada perkerasan jalan, sedangkan untuk metode SDI hanya mengamati 4 unsur kerusakan, sehingga hasil yang ditampilkan berbeda.
\end{abstract}

Kata kunci: PCI; SDI; Jalan

\section{PENDAHULUAN}

Provinsi Jawa barat membutuhkan peranan prasarana jalan raya dalam pembangunan regional, dalam memenuhi harapan bagi pengguna jalan dilakukan upaya kegiatan perencanaan, pelaksanaan dan pemeliharaan jalan raya sudah seharusnya dilakukan dengan baik.

Pada Jalan Jatisari terdapat di Kabupaten Karawang Provinsi Jawa Barat juga mengalami kondisi tersebut. hal tersebut dapat menimbulkan dampak negatif terhadap pertumbuhan daerah. yang dimana seperti pada jalan lainnya pertumbuhan lalu lintas meningkat setiap tahun dikarenakan bertambahnya jumlah penduduk, sehingga menyebabkan kerusakan pada konstruksi perkerasan jalan lentur berupa retak, lubang, pelepasan butir dan lainnya, merupakan faktor hambatan bagi pengguna jalan.

Dengan kondisi jalan seperti diatas maka dibutuhkan usaha yang lebih supaya kualitas pelayanan jalan tersebut terjaga, salah satu upaya tersebut adalah mengevaluasi kondisi kerusakan pada perkerasan jalan, yaitu dengan meninjau pengukuran terhadap kondisi permukaan jalan. Program peningkatan, pemeliharaan berkala dan 
pemeliharaan rutin membutuhkan nilai kondisi sebagai acuan dalam menentukan jenis program tersebut. Dengan pengamatan visual diperoleh nilai untuk memilih jenis penanganan jalan. Dalam melakukan evaluasi kondisi jalan bisa digunakan dua parameter pendekatan antara lain, Pavement Condition Index (PCI), dan Surface Distress Index (SDI). Setelah menentukan kondisi kerusakan tersebut, dilakukan upaya perbaikan untuk menangani kerusakan tersebut. Lalu, menentukan sisa umur perkerasan Jalan Raya Jatisari. Sehingga mengetahui berapa lama perkerasan Jalan Raya Jatisari dapat melayani pengguna jalan.

Berdasarkan latar belakang tersebut, penelitian ini akan menunjukkan kondisi kerusakan perkerasan jalan dari dua metode antara lain, Pavement Condition Index (PCI) dan Surface Condition Index (SDI).

Dari penjelasan latar belakang diatas, dalam penelitian ini ditemukan batasan masalah di antara lain:

1. penelitian menggunakan data sekunder, dikarenakan tidak survei secara langsung ke lokasi tersebut.

2. Pengamatan dilakukan secara visual melalui pencitraan satelit google street view.

Berdasarkan masalah yang dirumuskan pada rumusan masalah, maka maksud dari penelitian ini adalah:

1. Menganalisis tipe dan derajat kerusakan perkerasan jalan berdasarkan metode PCI dan SDI, serta memberikan alternatif penanganannya,

2. Menganalisis prediksi sisa umur.

\section{Perkerasan lentur jalan}

Perkerasan lentur adalah struktur solid yang terdiri dari banyak lapisan dengan konsistensi kekerasan dan daya dukung yang lain. Perkerasan lentur memiliki ciri khas berupa aspal sebagai lapisan pengikat. Seiring berjalannya waktu, aspal dapat mengalami penurunan kekuatan karean faktor lingkungan, misalnya air dan panas. Sedangkan struktur perkerasan lentur lambat laun akan mengalami kerusakan akibat beban berulang. Kerusakan pada perkerasan jalan dapat disebabkan oleh lalu lintas, air, material konstruksi, iklim, kondisi tanah dasar, dan pemadatan lapisan yang kurang maksimal (Sukirman, 1999). Penurunan akibat pembangunan utilitas, buruknya drainase, terlalu banyaknya kadar aspal, dan fatik/kelelahan perkerasan juga dapat menyebabkan kerusakan pada perkerasan (Croney \& Croney, 1998).

\section{Kerusakan perkerasan lentur}

Jenis kerusakan perkerasan lentur dapat dikategorikan sebagai berikut (Yoder \& Witczak, 1975; Bina Marga, 1995):

1. Deformasi, yaitu perubahan bentuk permukaan jalan dari muka/profil aslinya, terdiri dari kerusakan gelombang, alur, ambles, sungkus, mengembang, benjol, dan turun

2. Retak yang terjadi akibat regangan tarik melebihi izin, terdiri dari retak memanjang, melintang, diagonal, reflektif, blok, kulit buaya, dan bulan sabit

3. Kerusakan tekstur lapisan permukaan, dapat berupa terlepasnya butiran, kegemukan, polished agregat, permukaan terkelupas, dan stripping.

4. Lubang, tambalan, dan persilangan sebidang

5. Kerusakan di tepi perkerasan yang dapat berupa reta, pecah, dan penurunan bahu jalan

\section{Metode PCI}

Sebagai bagian dari usaha pemeliharaan jalan, maka survey kondisi jalan secara berkala perlu dilakukan. Hal ini penting agar didapat kondisi jalan yang akurat sehingga dapat direncanakan teknik perbaikan yang tepat. Untuk mendapatkan tipe, tingkat, dan luas kerusakan yang terjadi pada kondisi perkerasan jalan dapat digunakan Indeks kondisi perkerasan atau PCI (Pavement Condition Index). Penilaian kondisi perkerasan pada metode PCI dijabarkan dari nilai 0 (nol) sampai nilai 100 (seratus) dengan kategori antara lain, sempurna (excellent), sangat baik (very good), baik (good), sedang (fair), Buruk (poor), sangat Buruk (very poor) dan gagal (failed). Sebelum dilakukan analisis PCI, ditentukan tipe kerusakan yang terjadi pada jalan berdasarkan tingkat kerusakan yaitu, low (L), medium (M), dan High (H) (Arhin, Williams, Ribbiso, \& Anderson, 2015; Setyawan, Nainggolan, \& Budiarto, 2015; ASTM, 2008). Untuk lebih jelas, ditampilkan pada Tabel 1 (Shahin, 2000). 
Tabel 1 Jenis penanganan untuk nilai PCI tertentu

\begin{tabular}{ccc}
\hline Nilai PCI & Kondisi & Jenis penanganan \\
\hline $0-10$ & Gagal (failed) & Rekonstruksi \\
$11-25$ & Sangat buruk (very poor) & Rekonstruksi \\
$26-40$ & Buruk (poor) & Berkala \\
$41-55$ & Sedang (fair) & Rutin \\
$56-70$ & Baik (good) & Rutin \\
$71-85$ & Sangat baik (very good) & Rutin \\
$86-100$ & Sempurna (excellent) & Rutin \\
\hline
\end{tabular}

\section{Metode SDI}

Survey kondisi jalan tentang pemeliharaan rutin dari manual konstruksi dan bangunan yang diberikan oleh Bina Marga dalam Manual Survei Kondisi Jalan untuk Pemeliharaan Rutin No 001-01/M/BM/2011 (Direktorat Jenderal Bina Marga, 2011). Pengamatan dilakukan dua kali dalam setahun, yang dimana pengamatan pertama kali dilakukan dari bulan April sampai bulan Juni. Lalu, pengamatan kedua dilakukan dari bulan Oktober hingga bulan ke November. Pengamatan ini berdasarkan data titik referensi yang diberikan oleh Bina Marga. Pengamatan yang tepat dilakukan pada saat sebelum hujan dan sesudah hujan. Kerusakan yang sangat kecil akan meningkat dengan waktu yang sedikit menjadi besar saat musim hujan, hal tersebut menjadi pertimbangan dasar saat melakukan survey.

Dalam melakukan analisis SDI perlu diperhatikan 4 faktor yang digunakan sebagai bantuan yaitu:

1. Persentase luas keretakan

Faktor ini meliputi luas bagian permukaan jalan yang mengalami kerusakan retak. Persentasi dari total area permukaan jalan yang retak dapat diperkirakan.

2. Rata-rata lebar retak

Faktor ini menjelaskan pada permukaan perkerasan yang diuku rterdapat jarak antara dua bidang retakan.

3. Jumlah lubang/km

Sepanjang $1 \mathrm{Km}$ yang ditentukan jumlah lubang yang terdapat pada permukaan jalan.

4. Rata-rata kedalaman bekas roda (rutting)

beban roda kendaraan menyebabkan Penurunan pada suatu bidang permukaan jalan.

Analisis ini bisa dilihat pada Tabel 2 hingga Tabel 5 (Direktorat Jenderal Bina Marga, 2011)

Tabel 2 Penilaian luas retak

\begin{tabular}{cc}
\hline Kategori luas retak & Nilai SDI $^{\mathrm{a}}$ \\
\hline Tidak ada & - \\
$<10 \%$ & 5 \\
$10 \%-30 \%$ & 20 \\
$>30 \%$ & 40 \\
\hline
\end{tabular}

Tabel 3 Penilaian lebar retak

\begin{tabular}{cc}
\hline Kategori lebar retak & Nilai SDI $^{\mathrm{b}}$ \\
\hline Tidak ada & - \\
Halus $<1 \mathrm{~mm}$ & - \\
Sedang $1 \mathrm{~mm}-3 \mathrm{~mm}$ & - \\
Lebar $>3 \mathrm{~mm}$ & Nilai SDI ${ }^{\mathrm{a}} \times 2$ \\
\hline
\end{tabular}


Tabel 4 Penilaian jumlah lubang/km

\begin{tabular}{cc}
\hline Kategori jumlah lubang & Nilai SDI $^{\mathrm{c}}$ \\
\hline Tidak ada & - \\
$<10 / \mathrm{Km}$ & Nilai SDI ${ }^{\mathrm{b}}+15$ \\
$10 \mathrm{Km}-50 \mathrm{Km}$ & Nilai SDI +775 \\
$>50 \mathrm{Km}$ & Nilai SDI $^{\mathrm{b}}+100$ \\
\hline
\end{tabular}

Tabel 5 Penilaian bekas roda

\begin{tabular}{cc}
\hline Kategori bekas roda & Nilai SDI $^{\mathrm{d}}$ \\
\hline Tidak ada & - \\
$<10 \%$ & Nilai SDI $^{\mathrm{c}}+5 \times 0.5$ \\
$10 \%-30 \%$ & Nilai SDI $+5 \times 2$ \\
$>30 \%$ & Nilai SDI $+5 \times 4$ \\
\hline
\end{tabular}

Untuk menilai kondisi perkerasan jalan yang di survei, dapat dilihat Tabel 6.

Tabel 6 Batas nilai indeks kondisi permukaan jalan

\begin{tabular}{cc}
\hline Kondisi & Indeks kondisi permukaan jalan \\
\hline Baik & $0 \leq 50$ \\
Sedang & $50 \mathrm{~s} / \mathrm{d} 100$ \\
Rusak ringan & $100 \mathrm{~s} / \mathrm{d} 150$ \\
Rusak berat & $>150$ \\
\hline
\end{tabular}

\section{METODE PENELITIAN}

Penelitian ini dimulai dengan mendapatkan data primer berupa jenis dan dimensi kerusakan ruas Jalan Raya Jatisari yang dimana akan digunakan untuk menghitung menggunakan metode PCI dan SDI diperoleh dari pengamatan visual menggunakan aplikasi satelit google earth dan google street. Penelitian ini berlokasi di Jalan raya jatisari, Karawang. Jalan raya jatisari merupakan bagian dari Jalur pantura yang berstatus Jalan Nasional dengan kode ruas 2200513. Jalan ini membentang sepanjang $2.8 \mathrm{Km}$. raya jatisari terdiri dari 4 lajur 2 arah dengan permukaan berupa perkerasan lentur. Gambar 1 merupakan peta lokasi Jalan Raya Jatisari.

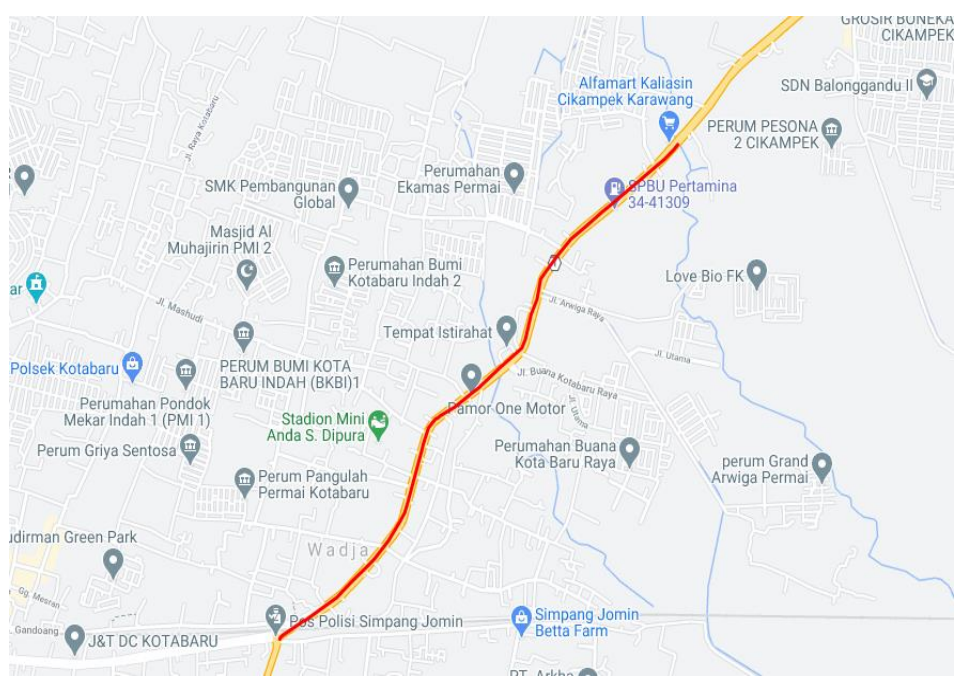

Gambar 1 Peta lokasi ruas Jalan Raya Jatisari (Cikampek) 
Berikut merupakan beberapa tahapan metodologi yang dilakukan dalam penelitian:

1. Studi literatur mengenai perkerasan lentur jalan raya, metode yang dipakai dalam mendesain jalan raya, dan analisis kerusakan jalan raya berupa kerusakan lubang, tambalan, dan retak alur.

2. Melakukan survey pengamatan kondisi kerusakan jalan, berupa jenis dan dimensi kerusakan per 50 meter sepanjang $2,8 \mathrm{~km}$.

3. mengevaluasi kondisi perkerasan jalan raya melalui metode PCI dan SDI.

4. Membandingkan nilai kondisi jalan berdasarkan metode PCI, IRI,dan SDI

5. Memilih jenis penanganan yang tepat untuk nilai kondisi jalan berdasarkan beberapa metode yang diuji.

6. Mengambil kesimpulan dan saran dari penelitian yang dilakukan.

\section{HASIL DAN PEMBAHASAN}

Ruas Jalan Nasional Jatisari memiliki 4 lajur dan 2 arah dengan lebar satu lajur sebesar 3,5 meter. Koordinat awal jalan ini adalah 6 $6^{\circ} 24^{\prime} 32^{\prime}$ ' $\mathrm{S}$ dan $107^{\circ} 29^{\prime} 8^{\prime}$ ' $\mathrm{E}$, lalu koordinat akhir jalan ini adalah $6^{\circ} 23^{\prime} 27^{\prime}$ ' $\mathrm{S}$ dan $107^{\circ} 30^{\prime} 6^{\prime}$ ' E. Di sekitar ruas jalan nasional Jatisari terdapat permukiman sebagai tata guna lahan. Jalan ini sering dilewati oleh kendaraan muatan sedang maupun besar yang mengantar logistik dari pabrik ke tujuan. Gambar 2 menampilkan titik penempatan survei kerusakan pada penelitian ini.

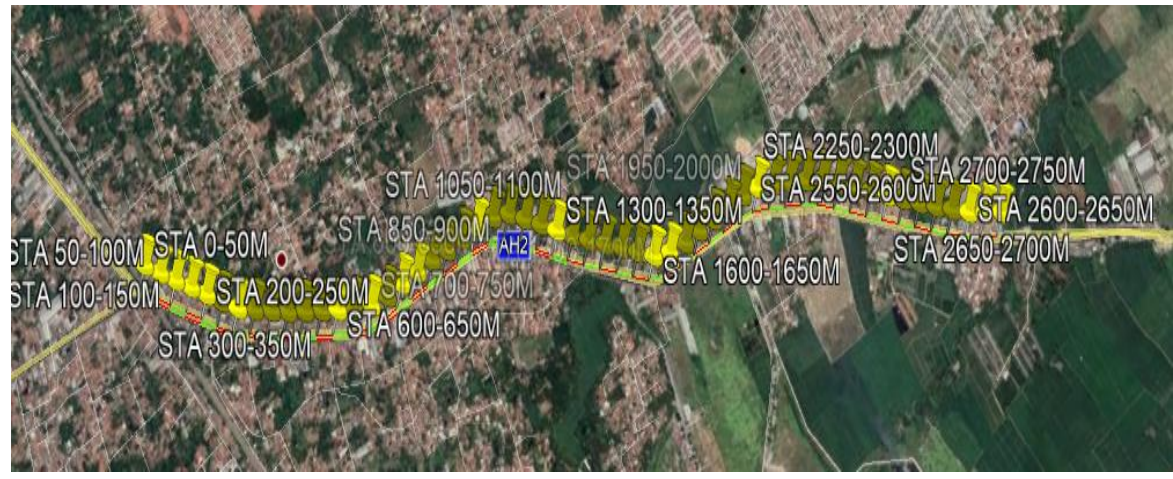

Gambar 2 Titik penempatan survei Jalan Nasional Jatisari

\section{Analisis nilai PCI}

Sebelum melakukan analisis nilai PCI, sangat diperlukan data dimensi dan jenis kerusakan yang diteliti. Gambar 3 menunjukkan hasil rekapan jenis kerusakan sepanjang lokasi observasi.

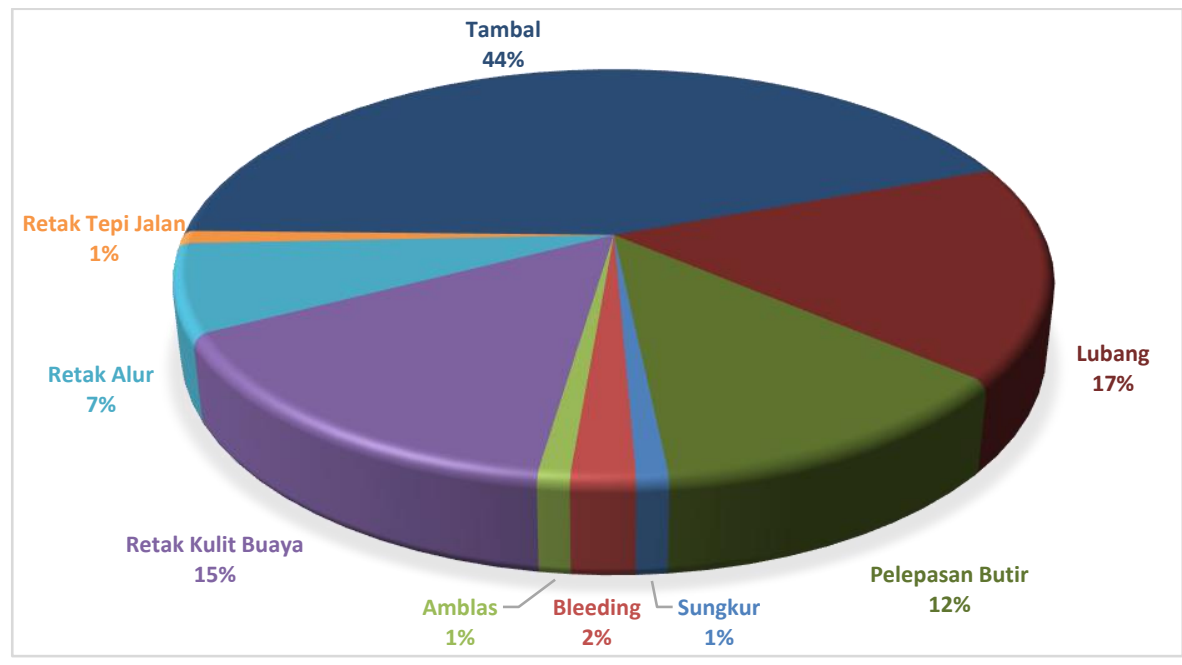

Gambar 3 Grafik jenis kerusakan di ruas Jalan Nasional Jatisari

Dari Gambar 3 dapat dijelaskan bahwa data jenis kerusakan di ruas jalan nasional Jatisari terdapat beberapa jenis kerusakan yaitu, retak kulit buaya memiliki 15\% kerusakan, lubang memiliki 17\% kerusakan, pelepasan butir memiliki $12 \%$ kerusakan, retak alur memiliki 7\% kerusakan, namun yang memilika tingkat kerusakan terbesar adalah kerusakan tambalan memiliki $44 \%$ kerusakan. beberapa kerusakan kecil yaitu sungkur memiliki $1 \%$ 
kerusakan, kegemukan (bleeding) memiliki 2\%, amblas memiliki 1\% kerusakan, dan retak tepi jalan memiliki $1 \%$ kerusakan. Dari banyaknya kerusakan tersebut masing - masing memiliki tingkat kerusakan yang berbeda-beda.

Dalam perhitungan nilai PCI, dilakukan dalam beberapa tahap sebagai berikut:

\section{Density (kadar kerapatan)}

Density atau kadar kerusakan adalah persentase luas suatu jenis kerusakan perkerasan jalan terhadap luasan suatu unit segmen yang diteliti dalam satuan meter persegi atau meter panjang. Persamaan 1 digunakan untuk mencari nilai densitas:

$$
\text { densitas }=\frac{A d}{A s} \times 100 \%
$$

dengan Ad = Luas total satu jenis kerusakan untuk tiap tingkat kerusakan (m2), As = Luas total satu unit segmen $(\mathrm{m} 2)$

Contoh perhitungan pada STA 0.00-50M arah pamanukan, diketahui Luas kerusakan 6,396 $\mathrm{m}^{2}$, jenis kerusakan bleeding dengan tingkat kerusakan sedang. Sedangkan luas total unit segmen sebesar $175 \mathrm{~m}^{2}$. Sehingga denga Persamaan 1 diperoleh densitas sebesar $1,83 \%$.

\section{Deduct Value (Nilai pengurang)}

Grafik hubungan density dan deduct value menghasilkan nilai pengurang untuk semua jenis kerusakan. Setiap jenis dan tingkat kerusakan yang terjadi membedakan nilai Deduct value. Berikut salah satu contoh grafik hubungan densitas dan deduct value dengan jenis kerusakan bleeding, dalam contoh perhitungan ini bisa ditampilkan pada Gambar 4.

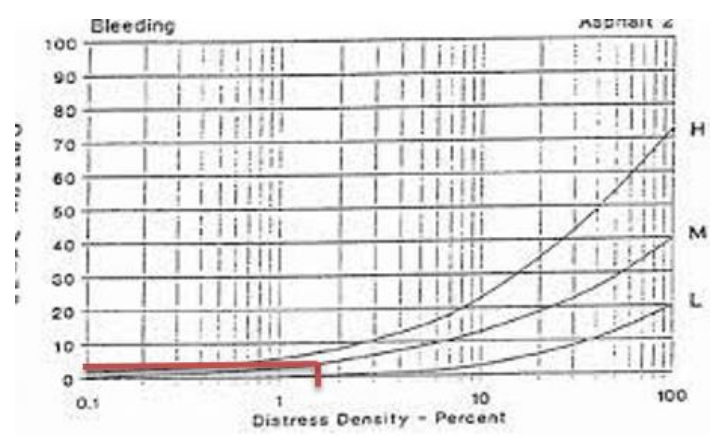

Gambar 4 Grafik hubungan density dan deduct value bleeding

Berdasarkan gambar diatas, nilai deduct value yang diperoleh sebesar 4.

\section{Total deduct value (TDV)}

Setiap tipe dan tingkat kerusakan yang terjadi pada penelitian bisa mendapatkan nilai Total Deduct Value (TDV), nilai TDF diperoleh dari jumlah nilai tiap individu deduct value. Untuk STA 0-50M, total nilai DV sebesar 4.

4. Nilai izin dari deduct (m)

Sebelum melanjutkan menghitung nilai PCI, dilakukan pengecekan nilai izin terlebih dahulu. Dalam penelitian ini, jika hanya terdapat satu deduct value memiliki nilai $>5$ untuk penelitian lapangan udara dan untuk penelitian jalan $>2$, maka nilai TDV digunakan sebagai nilai $C D V$, Apabila tidak maka dilanjutkan pada tahap khusus. Yang pertama mengurutkan nilai deduct value dari nilai terbesar ke nilai terkecil. Lalu, nilai m ditentukan dengan Persamaan 2.

$$
\mathrm{m}=1+(9 / 98) *(100-\mathrm{HDV}) \leq 10
$$

dimana HDV adalah high deduct value. Apabila jumlah nilai data deduct value melebihi nilai m, maka nilai data deduct value yang melewati nilai ijin $\mathrm{m}$ dikali dengan sisa nilai $\mathrm{m}$ tersebut. Jika jumlah nilai data deduct value tidak melebihi nilai m. maka nilai $\mathrm{m}$ tidak dipakai, dan dapat dilanjutkan analisis berikutnya.

$$
\mathrm{m}=1+(9 / 98) *(100-4)=9,8163 \leq 10
$$

karena nilai m kurang dari 10, maka nilai m tidak berlaku untuk STA ini.

\section{Corrected Deduct Value (CDV)}

Dengan menggunakan grafik hubungan nilai TDV dengan nilai CDV diperoleh nilai Corrected Deduct Value (CDV) dengan beberapa tahap sebagai berikut: 
a. Mengurutkan nilai TDV dari nilai terbesar ke nilai terkecil.

b. Melakukan iterasi terhadap nilai deduct value. pada iterasi pertama, nilai TDV dijumlahkan dan dapat menentukan nilai q, untuk nilai q dapat ditentukan berdasarkan nilai deduct value yang lebih dari 2, apabila nilai deduct value kurang dari nilai 2 maka, nilai q tidak terhitung.

c. Iterasi dilakukan hingga sisa nilai q diperoleh sebesar 1 .

d. Setelah melakukan iterasi, dapat grafik hubungan nilai TDV dan nilai CDV dengan pemilihan lengkung kurva sesuai dengan nilai q yang didapat (Gambar 5).

e. Nilai CDV terbesar pada proses iterasi yang diteliti menjadi nilai CDV maksimum.

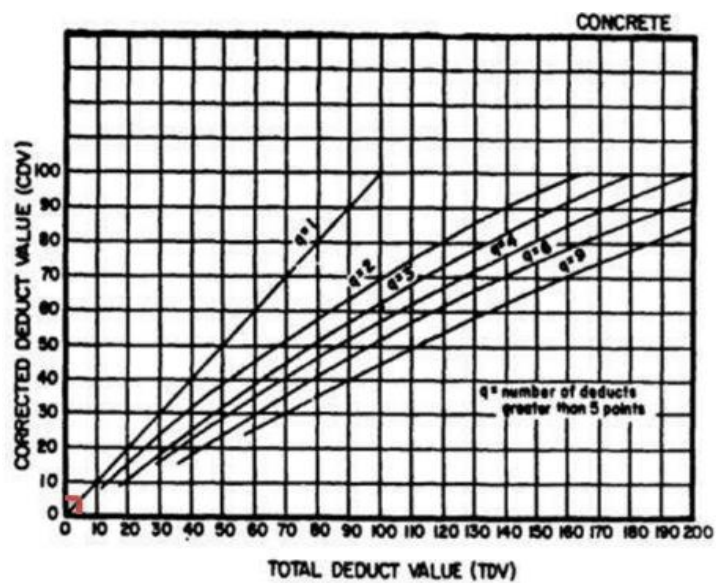

Gambar 5 Grafik hubungan nilai TDV dengan CDV

Berdasarkan gambar diatas bisa dijelaskan bahwa STA 0-50M diperoleh nilai $\mathrm{q}=1$ dan nilai CDV sebesar 4.

6. Nilai PCI

Dalam analisis nilai PCI, dibutuhkan nilai CDV maksimum untuk mendapatkan nilai PCI menggunakan Persamaan 3.

$$
\mathrm{PCI}=100-\mathrm{CDVmaks}
$$

Setelah mendapatkan nilai PCI, melihat tabel 2 untuk mengetahui kondisi perkerasan jalan.

Untuk nilai PCI STA 0-50M bisa dihitung seperti berikut:

$$
\text { PCI }=100-4=96(\text { SEMPURNA })
$$

Langkah perhitungan yang sama dilakukan untuk unit observasi lainnya, sehingga didapat nilai PCI ruas Jalan Raya Jatisari seperti disajikan dalam grafik rekapitulasi nilai PCI untuk arah Pamanukan (Gambar 6) dan Cikampek (Gambar 7).

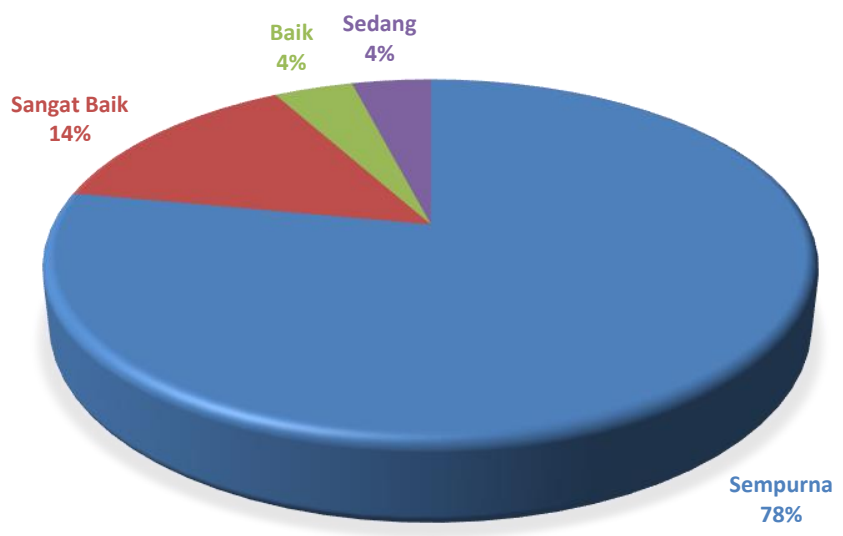

Gambar 6 Grafik rekapitulasi kondisi kerusakan Jalan Jatisari (arah Pamanukan) menggunakan metode PCI 


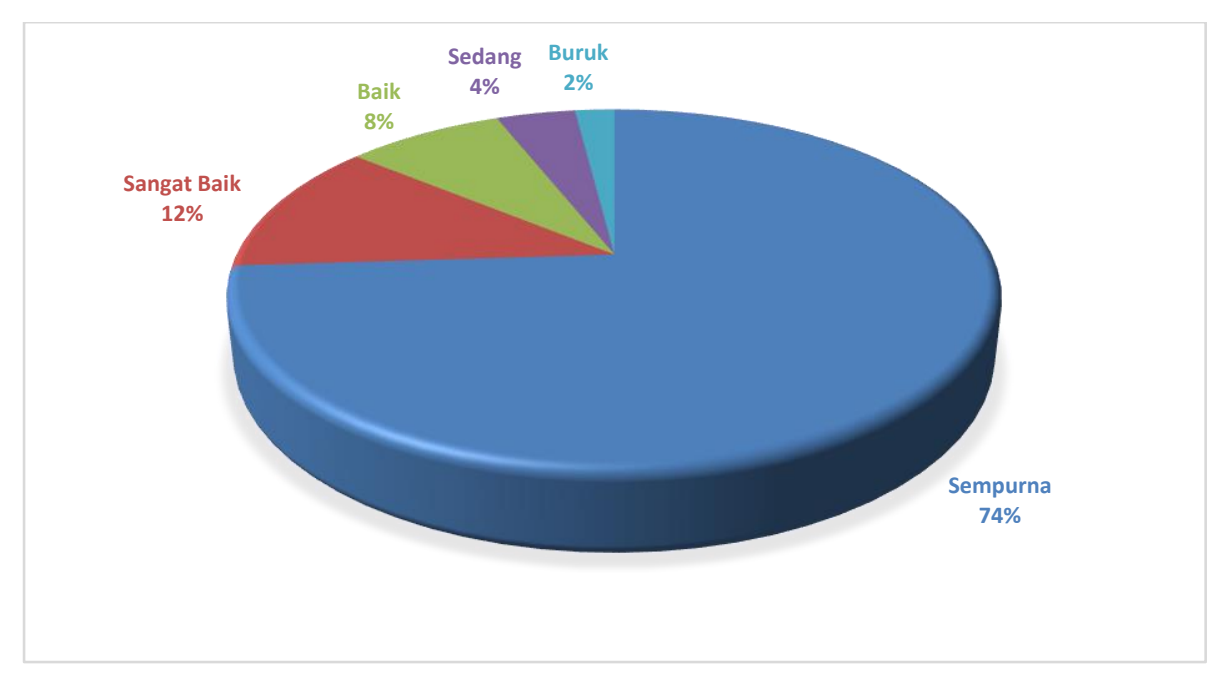

Gambar 7 Grafik rekapitulasi kondisi kerusakan Jalan Jatisari (arah Cikampek) menggunakan metode PCI

Berdasarkan Gambar 6 dan Gambar 7, bisa dijelaskan bahwa kondisi perkerasan Jalan Jatisari arah Pamanukan digolongan sempurna sebesar $78 \%$, sangat baik $14 \%$, baik $4 \%$ dan sedang $4 \%$. Sedangkan kondisi perkerasan jalan jatisari arah Cikampek kondisi perkerasan Jalan Jatisari terdapat golongan sempurna sebesar 74\%, sangat baik 12\%, baik $8 \%$, sedang $4 \%$, dan buruk $2 \%$.

Melihat kondisi perkerasan yang telah mengalami kerusakan sebaiknya segera dilakukan perbaikan. Metode perbaikan yang digunakan harus disesuaikan dengan jenis kerusakannya sehingga diharapkan dapat meningkatkan kondisi perkerasan jalan tersebut.

\section{Analisis nilai SDI}

Berdasarkan data kerusakan jalan yang diperoleh dari survei secara virtual melalui google streets, maka selanjutnya dapat dilakukan penilaian kondisi untuk menentukan nilai SDI pada masing - masing ruas yang sudah ditentukan. Tabel 7 menunjukkan hasil perhitungan SDI untuk STA 300 - 350M arah Cikampek

Tabel 7 Hasil perhitungan SDI untuk STA 300 - 350M arah Cikampek

\begin{tabular}{ccccc}
\hline no & tipe kerusakan & survei & perhitungan & SDI \\
\hline 1 & \%luas retak & $<10 \%$ & 5 & 5 \\
2 & lebar retak & $>5 \mathrm{~mm}$ & $5 \times 2$ & 10 \\
3 & jumlah lubang & $<10 / \mathrm{Km}$ & $10+15$ & 25 \\
4 & bekas roda & tidak ada & - & - \\
\hline \multicolumn{3}{c}{ SDI } \\
\hline
\end{tabular}

\section{Mencari persentase luas retak}

Misalnya pada STA 300 - 350M, diketahui bahwa luas retak pada perkerasan tersebut adalah 4,116 ${ }^{2}$. Maka untuk mendapat nilai persentase luas retak menggunakan Persamaan 4.

$$
\text { \%luas retak }=\frac{\text { luas kerusakan }}{\text { luas segmen }} \times 100
$$

Diketahui bahwa panjang segmen jalan adalah 50M dan lebar segmen jalan adalah 7M. maka didapat nilai persentase luas retak. Dari Persamaan 4, didapat nilai persentase luas retak sebesar 1,176\%. Lalu, dibandingkan dengan Tabel 8. berdasarkan tabel tersebut diperoleh bahwa nilai persentase luas retak $<10 \%$, maka diperoleh nilai $\mathrm{SDI}^{\mathrm{a}}$ sebesar 5 .

2. Mencari nilai lebar retak

Pada STA 300 - 350M, berdasarkan survei visual melalui google streets, disimpulkan bahwa lebar retak pada perkerasan jalan $>5 \%$ dilihat dari Tabel 9. maka untuk mendapat nilai SDI ${ }^{\mathrm{b}}$ sebesar 10 . 


\section{Mencari nilai jumlah lubang}

di sekitar ruas STA 300 - 350M terdapat lubang yang dimana <10/Km, maka nilai SDI ${ }^{\mathrm{c}}$ diperoleh sebesar 25.

4. Mencari nilai bekas roda

di sekitar ruas STA 300 - 350M tidak ada bekas roda yang dimana nilai SDI ${ }^{\mathrm{d}}$ adalah 0.

5. Menghitung nilai SDI akhir

Berdasarkan data perhitungan pada Tabel 8, diperoleh total nilai SDI adalah 30. Angka tersebut menunjukkan bahwa indeks kondisi permukaan jalan tergolong baik.

Dengan langkah yang sama, dihitung nilai SDI untuk seluruh unit survey. Hasil perhitungan menunjukkan bahwa indeks permukaan jalan nasional Jatisari, karawang tergolong baik pada semua unit sampel. Hal ini berbeda dengan metode PCI dimana terdapat hasil yang beragam, bahkan ada 1 sampel yang mendapat nilai Buruk. Perbedaan ini terjadi karena metode SDI hanya menggunakan 4 unsur kerusakan, sehingga terdapat kerusakan yang tidak terukur di metode SDI namun dapat terukur di metode PCI. Hal ini menjadi temuan penting yang menggambarkan perbedaan kedua metode tersebut. Jika dalam pelaksanaan dibutuhkan ketelitian yang tinggi, maka metode PCI lebih tepat digunakan. Metode SDI dapat digunakan jika dikombinasikan dengan metode IRI agar kondisi jalan dapat lebih terukur secara akurat.

\section{KESIMPULAN DAN SARAN}

\section{Kesimpulan}

Dalam penelitian ini analisis yang dilakukan adalah untuk mengetahui kondisi perkerasan Jalan Raya Jatisari, Karawang. Berdasarkan hasil analisis yang dilakukan dapat dibuat kesimpulan sebagai berikut.

1. Berdasarkan hasil analisis sisa umur paling besar pada tahun 2019 yaitu sebesar 19,91 tahun yang dimana masih ada layanan sisa umur sebesar 99,54\% dan paling kecil pada tahun 2038 dengan sisa umur 0 tahun dengan layanan sisa umur sebesar 0 .

2. Berdasarkan hasil analisis SDI, menunjukkan indek kondisi permukaan kedua arah perkerasan Jalan Raya Jatisari adalah baik.

3. Berdasarkan hasil analisis PCI, menunjukkan bahwa indeks kondisi perkerasan arah Pamanukan memiliki golongan sempurna sebesar $78 \%$, sangat baik $14 \%$, baik $4 \%$ dan sedang $4 \%$. Sedangkan untuk arah Cikampek memiliki golongan sempurna sebesar $74 \%$, sangat baik $12 \%$, baik $8 \%$, sedang $4 \%$, dan buruk $2 \%$.

4. Berdasarkan hasil analisis, penelitian menggunakan metode PCI dan SDI menunjukkan hasil yang berbeda, yang dimana nilai rata-rata PCI arah Pamanukan diperoleh sebesar 90,44\% dan arah Cikampek diperoleh sebesar 89,7\%. Sedangkan hasil analisis SDI diperoleh nilai kondisi baik secara keseluruhan. dikarenakan dalam metode PCI mengamati semua kerusakan yang terjadi pada perkerasan jalan, sedangkan untuk metode SDI hanya mengamati 4 unsur kerusakan, sehingga hasil yang ditampilkan berbeda.

\section{Saran}

Diharapkan penilitian berikutnya dapat dilakukan dengan alat-alat yang cukup, dan dapat dilakukan survei secara langsung di lokasi studi kasus. Karena survei melalui aplikasi google streets masih kurang akurat.

\section{DAFTAR PUSTAKA}

Arhin, S. A., Williams, L. N., Ribbiso, A., \& Anderson, M. F. (2015). Predicting Pavement Condition Index Using International Roughness Index in a Dense Urban Area. Journal of Civil Engineering Research, 5(1), 1017.

ASTM. (2008). Standard Practice for Road and Parking Lots Pavement Conditions Survey: D 6433-07. Pennsylvania: ASTM.

Bina Marga. (1995). Manual Pemeliharaan Rutin Untuk Jalan Nasional dan Jalan Propinsi. Jakarta: Departemen Pekerjaab Unun.

Croney, D., \& Croney, P. (1998). THE DESIGN AND PERFORMANCE OF ROAD PAVEMENTS (Third ed.). New York: McGraw-Hill. 
Direktorat Jenderal Bina Marga. (2011). Indonesia Integrated Road Management System (IIRMS) No. SMD-03/RC Panduan Survei Kondisi Jalan. Jakarta: Kementerian Pekerjaan Umum.

Direktorat Jenderal Bina Marga. (2011). SURVEI KONDISI JALAN UNTUK PEMELIHARAAN RUTIN No. 001-01 / $M$ / BM / 2011. Jakarta: Kementerian Pekerjaan Umum.

Setyawan, A., Nainggolan, J., \& Budiarto, A. (2015). Predicting the remaining service life of road using pavement condition index. Procedia Engineering, 125, 417-423.

Shahin, Y. M. (2000). Pavement management for airports, roads, and parking lots. Boston: Kluwer.

Sukirman, S. (1999). Perkerasan Lentur Jalan Raya. Bandung: Nova.

Yoder, E. J., \& Witczak, M. W. (1975). Principles of Pavement Design. New York: A Wiley-Interscience Publication. 